\title{
High-speed three-dimensional imaging of the pulmonary alveoli
}

\author{
Eman Namati, Carolin Unglert*, Brett Bouma, Guillermo Tearney \\ From 2nd Scientific Meeting of the Head and Neck Optical Diagnostics Society \\ San Francisco, CA, USA. 23-24 January 2010
}

Investigating the structure and function of pulmonary alveoli in vivo is crucial for understanding the normal and diseased lung. In particular, understanding the three-dimensional geometry and relationship of the terminal alveoli to their neighboring alveoli, alveolar ducts and acini during respiration would be a major advance. However, the lung is an inherently difficult organ to image in vivo and the peripheral lung has many compounding challenges not limited to its highly scattering micro architecture, large motion artifacts and difficult access through the bronchial tree.

In this study, we image the alveoli of fixed pig lungs using a high-speed high-resolution optical frequency domain imaging (OFDI) system that is endoscopically compatible for future in vivo imaging of human alveoli. Core imaging components include a rapidly swept wavelength source centered at $1310 \mathrm{~nm}$ resulting in an A-line depth scan rate of $62,500 \mathrm{~Hz}$, a polarization diverse dual balanced receiver, and a high speed data acquisition system. Whole lungs were excised from normal piglets and inflation fixed at $15 \mathrm{~cm} \mathrm{H} 2 \mathrm{O}$ pressure using a modified Heitzman fixation technique. Lungs were air dried in a heated oven and sectioned into $500 \mu \mathrm{m}$ slices. Three-dimensional datasets were acquired from lung slices with $512 \times 512 \times 1024$ voxels and a voxel dimension of $5 \times 5 \times 8 \mu \mathrm{m}$. Datasets were acquired at 122 frames per second and 0.23 volumes per second - indicating the potential to acquire a three-dimensional volume within a single human respiratory cycle.

OFDI images reveal clear delineation of alveolar septal walls, demonstrating that high-speed three-dimensional visualization of air filled alveoli is feasible. The fixed lung data provides a strong foundation for investigating

Wellman Centre for Photomedicine, Harvard Medical School, Boston, USA the 3D structure and function of alveoli in vivo and suggests great promise for advancing our knowledge of the functional unit of the lung.

Published: 29 October 2010

doi:10.1186/1758-3284-2-S1-011

Cite this article as: Namati et al: High-speed three-dimensional imaging of the pulmonary alveoli. Head \& Neck Oncology 2010 2(Suppl 1):011.
Submit your next manuscript to BioMed Central and take full advantage of:

- Convenient online submission

- Thorough peer review

- No space constraints or color figure charges

- Immediate publication on acceptance

- Inclusion in PubMed, CAS, Scopus and Google Scholar

- Research which is freely available for redistribution

Submit your manuscript at www.biomedcentral.com/submit
C Biomed Central 